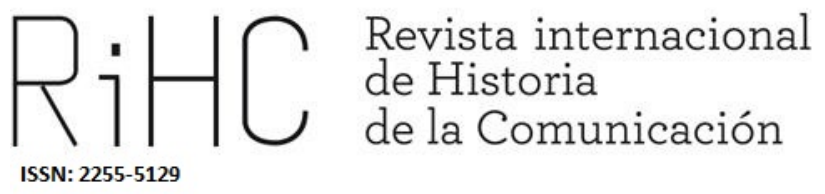

\title{
EL PALETO (1902- 1936), ESTUDIO DE UN CASO DE PRENSA LOCAL EN LA CIUDAD DE OSUNA
}

El Paleto (1902-1936), study of a local newspaper of the city of Osuna

DOI: http://dx.doi.org/10.12795/RiHC.2019.i13.08

Recibido: 15/10/2019

Aceptado: $27 / 11 / 2019$

Publicado:15/12/2019

María Jesús Moscoso Camúñez

Universidad Sevilla, España

mjesusmoscosocamunez@gmail.com

ORCID (iD) 0000-0002-5507-0298 
Resumen: Hablar de El Paleto supone hacer referencia al periódico más longevo de la localidad de Osuna (Sevilla). Más exactamente desde 1902 a 1936. Treinta y cuatro años en los que el periódico tuvo que hacer frente a numerosas vicisitudes así como a los diferentes regímenes políticos que se sucedieron durante este periodo histórico en España. Se incluye un recorrido desde los inicios del periodismo en Osuna, desde 1882 hasta la actualidad, para hacer hincapié en el valor de El Paleto: sus orígenes, su estructura y, sobre todo, su contenido más interesante y atractivo a través del que comprobaremos qué línea editorial adopta el rotativo atendiendo a quién se encuentre en el poder en uno u otro momento durante su existencia. Con el objetivo de estudiar en profundidad el rotativo, procederemos a un análisis de contenido para llegar a las conclusiones que nos permitirán conocer más acerca de El Paleto.

Palabras clave: Prensa, Osuna, Local, Sevilla, Paleto

\begin{abstract}
Talking about El Paleto means talking about the longest running newspaper in the town of Osuna, in the province of Seville. More precisely from 1902 until 1936. Thirty four years during which the newspaper had to face numerous difficulties, such as the different political regimes that took place over this historical period in Spain. A journey back to the beginning of journalism in Osuna, from 1882 upto now with a focus on El Paleto: its origin, its structure and, above all, its most interesting content. Through this process, we will look at the editorial line the paper adopted depending on the government that happened to be in power in the specific moments throughout history. With the objective of studying this newspaper, we will analyze the contents of it in order to know more about El Paleto.
\end{abstract}

Keywords: Press, Osuna, Local, Seville, Paleto

\title{
1 Introducción
}

\subsection{Los estudios de la prensa local}

Situar a El Paleto, cronológicamente hablando, supone ceñirnos a dos momentos históricos fundamentales en la historia de España: el año en el que Alfonso XIII alcanzaba la mayoría de edad (1902) y el inicio de la guerra civil (1936). Una etapa histórica de lo más convulsa durante la que se publicará el periódico más longevo de la villa ducal de Osuna.

El nacimiento de El Paleto cuenta con el respaldo de la Ley de Policía de Imprenta. Legislación que favorecerá, desde su promulgación el 26 de julio de 1883, la proliferación de impresos y la actividad periodística tal y como muy bien cita María José 
Ruiz Acosta ${ }^{1}$. Aunque estuvo vigente hasta la guerra civil española, no tuvo efecto durante la Dictadura de Primo de Rivera ni durante la II República y fue sustituida en 1938 por la muy restrictiva Ley de Prensa en la España de lo que ya era régimen de Franco.

Acometemos, por tanto, un estudio histórico que, siguiendo los postulados de diversos autores en sus obras de investigación acerca de la historia en general y de la del periodismo en particular, nos hace comprender la evolución que la humanidad ha tenido. Entre otros, destaca la labor de Antonio Miguel Bernal que propone, en primer lugar, desterrar mitos así como prejuicios sobre la historia local. Para el autor, algo tendrá esta forma de concebir la historia cuando es el género más "antiguo y primigenio" ${ }^{2}$. Compartimos los postulados de Bernal en tanto elevan esta historia local a una especie de historia total de una comunidad en la que se unen aspectos sociales, políticos, económicos o culturales con la vida cotidiana. Por su parte, la prensa se presenta como un pilar más con el que mostrar y dar forma a una realidad que, consecuencias inevitables del paso del tiempo, tuvo su propia razón de ser otrora y cuyos cambios y modificaciones no podemos percibir más que a través de diversos documentos gráficos que así nos la muestran. Entre estos, destaca el estudio del periodismo escrito:

[...] como medio privilegiado de la comunicación social, por su función formadorainformadora de la opinión pública y como estructura de poder para los que la rigen y domina, la prensa es al mismo tiempo, en sus más mínimos aspectos, el lugar nodal y vehículo de expresión ideológica, de la representación justificadora y del control social. [...] La prensa es por consiguiente, en sí, una estructura estructurante, clave en la época contemporánea, mientras otros medios de comunicación de masas no llegan a hacerle la competencia; y como proyecto coherente, aun cuando no tiene el porvenir por horizonte aparente de espera, es objeto específico para la historia ${ }^{3}$.

Atendiendo a lo señalado por el doctor Reig en su obra El Periodista en la Telaraña ${ }^{4}$, se pone de manifiesto las más que estrechas relaciones que existen entre el poder

\footnotetext{
${ }^{1}$ RUIZ ACOSTA, M. J. (1998): “La prensa sevillana de principios del siglo XX: el nacimiento de un nuevo modelo informativo (1898- 1914)”, en Reig García, R., y Ruiz Acosta, M. J.: Sevilla y su prensa:Aproximación a la historia del periodismo andaluz contemporáneo:(18981998). Universidad de Sevilla: Grupo de Investigación en Estructura, Historia y Contenidos de la Comunic ación. Sevilla, 1998, pp. 20- 21.

2 BERNAL, A.M.: "Riesgo y ventura de la historia local", en Actas del Primer Encuentro Provincial de Investigadores Locales. Diputación de Sevilla. Sevilla, 2003, pp. 13- 22.

${ }^{3}$ BOTRE, A.M.; DESVOIS, J.M. y AUBERT, P.: "Prensa e historia: para una historia objeto de la prensa. La prensa objeto polimorfo de la historia", en Castillo, S. (coord.): Estudios de Historia de España. Homenaje a Manuel Tuñón de Lara. Universidad Internacional Menéndez y Pelayo. Madrid, 1981, pp. 501- 502.

${ }^{4}$ REIG GARCÍA, R.: El periodista en la telaraña. Anthropos. Barcelona. 2007.
} 
(económico, político, financiero, etc.) y los medios de comunicación. En consecuencia, podemos llegar a entender el interés que las empresas y los distintos gobiernos tienen con respecto al control de la información surgiendo, así, disciplinas como puede ser la economía política encargada de "describir y examinar el significado de las instituciones responsables de la producción, distribución e intercambio de las mercancías de comunicación y regulación del mercado de comunicación" ${ }^{5}$. Todo ello nos lleva a pensar en el importante papel que juegan los gobiernos a la hora de regular los mercados para controlar la información y acabar con el pluralismo favoreciendo, en consecuencia, la concentración mediática, en la actualidad, y la manipulación de los contenidos que aparecen sesgados, tanto hoy en día como años, e incluso siglos, atrás.

Cuestiones actuales pero que también veremos cómo ocurrían en el pasado, y no solo a nivel nacional sino también local. De ahí que destaquemos la importancia y necesidad de llevar a cabo estudios de la prensa local con el fin de "[...] examinar su papel sociopolítico en el espacio local y constatar el hecho de que la historia de la prensa local de la época puede ser particularmente fecunda para la enseñanza de la Historia Contemporánea. [...]"6 . Todo ello teniendo en cuenta que el carácter de la prensa local no viene marcado: "tanto por el lugar donde se edita (no siempre en el mismo núcleo donde se imprime) como por la temática y, sobre todo, en función de los lectores a los que se dirige. Se trata de informar, opinar, etc., de acuerdo con los particulares y específicos intereses geográficos- sociales de una comunidad determinada".

Aunque, como indica Celso Almuiña, ello no implique un enfoque localista ${ }^{7}$.

\subsection{Estado de la cuestión}

A pesar de que existía un trabajo sobre la prensa del siglo XIX del ursaonense Rodolfo Álvarez Santaló y otros estudios sobre la prensa del siglo XX, no había un estudio en profundidad del periódico más longevo de la villa ducal de Osuna ${ }^{8}$. También los trabajos

\footnotetext{
${ }^{5}$ MOSCO, V.: “La Economía Política de la Comunicación: una actualización diez años más tarde” en CIC: Cuadernos de información y comunicación, (11). Universidad Complutense de Madrid. Madrid, 2006, p. 67.

${ }^{6}$ GARCÍA ANDREU, M. y SANTACREU, J.M.: “Prensa, sociedad y política provinciana (1902- 1939): el caso de Alicante", en Actas de las Jornadas sobre prensa y sociedad en la Murcia Contemporánea. Departamento de Historia Moderna. Murcia, 1994, p. 180.

${ }^{7}$ ALMUIÑA, C.: "Fondos y metodología para el análisis de la prensa local” en Fuentes y métodos de la Historia local, Instituto de Estudios Zamoranos "Floian de Ocampo". Zamora, 1991, p.389.

${ }^{8}$ ÁlVAREZ SANTALÓ, R.: “Osuna y su prensa en los últimos años del siglo XIX" en Archivo Hispalense: Revista histórica, literaria y artística. Tomo LXII (189). Sevilla, 1986. También del mismo: Rodríguez Marín, periodista (1880-1886). Fundación de Cultura “García Blanco" del Ayuntamiento de Osuna. Osuna, 1993; y La vieja prensa de Osuna y El Paleto. 2a Época. Fundación de Cultura "García Blanco" del Ayuntamiento de Osuna. Osuna, 2000.
} 
de Antonio Sánchez Morillo ${ }^{9}$. Esta situación que hacía necesaria abordar esta investigación sobre la prensa local de la que nace esta publicación ${ }^{10}$. El contenido de treinta y cuatro años de periodismo, su contenido y su trascendencia para la conformación de la idiosincrasia de un pueblo y su aportación al conocimiento de la evolución de la prensa, merecían un análisis de sus artículos y columnas con el fin de contribuir a la memoria. Así como las relaciones entre el poder y los medios de comunicación y, sobre todo, las relaciones de la política local con la nacional.

\subsection{Objetivos y metodología}

Teniendo en cuenta que El Paleto se muestra como una llave que nos permitirá acercarnos al pasado de la ciudad de Osuna, los objetivos que se han pretendido alcanzar con esta investigación son los siguientes:

1) Analizar la evolución de la prensa a nivel local.

2) Contribuir a la historia local mediante el análisis de las distintas noticias y artículos que dieron forma a los ejemplares publicados entre 1902 y 1936.

3) Proporcionar un soporte digital a todos los ejemplares que han ganado la batalla al paso del tiempo.

4) Mostrar la relación existente, así como las críticas y/ o alabanzas, entre el rotativo y el poder local. Para ello analizaremos las noticias relacionadas con aspectos políticos y de gestión, tanto a nivel local como provincial, autonómico o nacional así como de temas comprometidos - política o socialmente hablando -.

Acometer este estudio supuso enfrentarse a los pros y los contras de trabajar una temática de la que, prácticamente, había que partir de cero por la práctica inexistencia de estudios de investigación al respecto. En una primera toma de contacto, se procedió a la localización y lectura de los primeros 123 ejemplares que se publicaron entre 1902 y 1904 - de cuatro páginas cada uno -. El paso previo fue la búsqueda, documentación y catalogación de toda la prensa que en manos públicas (Biblioteca Municipal de Osuna) se encontraba ya que el grueso de los archivos se hallaba en manos privadas, más concretamente en la colección del sobrino político de Manuel Ledesma Vidal, José

\footnotetext{
${ }^{9}$ SÁNCHEZ MORILLO, A.: "La prensa en Osuna: contexto y fuentes", en Cuadernos de los Amigos de los Museos de Osuna, №. 9, 2007, pp. 86-88. SÁNCHEZ MORILLO, Antonio y Aguilar Majarón, Isabel: “EI periodismo en Osuna: una etnografía del oficio", en Cuadernos de los Amigos de los Museos de Osuna, №. 8, 2006, pp. 62-65.

${ }^{10}$ MOSCOSO CAMÚÑEZ, M.J. El Paleto ante los distintos regímenes políticos de la España de 1902 a 1936, Tesis doctoral. Puede consultarse en: (2017- 09- 21). Depósito de Investigación Universidad de Sevilla. idUS: https://idus.us.es/xmlui/handle/11441/71288
} 
Torrejón Real. A continuación, se procedió a la digitalización y lectura de todo el contenido de los ejemplares que se publicaron durante veintitrés años conservados (faltando varios años hasta completar los 34). Así, se clasificó y analizó el contenido publicado durante todos estos años con el fin de localizar aquellas noticias o artículos de opinión en los que se detectara la temática política y la postura del periódico.

Por otro lado, y con el fin de ofrecer una visión global de lo que significó el periodismo a nivel local, se tuvieron en cuenta las referencias que a la prensa del municipio se han realizado a lo largo del siglo XX, tanto en publicaciones periódicas como académicas $\mathrm{Y}$ que se citaron en el estado de la cuestión.

De este modo, abordamos un estudio microhistórico que, atendiendo a lo enunciado por Giovanni Levi, se muestra, en la mayoría de los casos, necesario si, además, no se han abordado estudios en profundidad al respecto:

El enfoque microhistórico aborda el problema de cómo acceder al conocimiento del pasado mediante diversos indicios, signos y síntomas. Es un procedimiento que toma lo particular como punto de partida (particular que es a menudo altamente específico e individual y sería imposible calificar de caso típico) y procede a identificar sus significados a la luz de su contexto específico. [...] ${ }^{11}$

Los estudios sobre prensa local son cada vez más valorados a la vez que la historia de la comunicación se muestra como un importante banco de recursos que permite sacar a la luz un pasado que, en muchos casos, se encuentra sesgado. De ahí la importancia de las fuentes hemerográficas que nos permitirán acceder a un tiempo y lugar concretos. Efectivamente, como afirma Vázquez Montalbán, la prensa es "medio de comunicación social hegemónico durante la segunda mitad del siglo XIX y primer cuarto del siglo XX"12.

De cualquier modo, el estudio de la historia de la prensa, de los medios y de la comunicación debiera ir acompañado de la disciplina de la que forma parte y de la que, a su vez, se desgaja: de la historia general y superar el estatus de fuente documental, a secas, que se le ha venido confiriendo en los últimos años:

No se trata, pues de una disciplina que pueda evolucionar al margen de la investigación histórica general. Es más, se integra en ella de tal modo que posee incluso la virtualidad de contribuir clarificadoramente a la reinterpretación de la historia general ${ }^{13}$.

\footnotetext{
${ }^{11}$ LEVI, G.: "Sobre microhistoria" en BURKE, P. (ed.): Formas de hacer historia. Alianza Editorial. Madrid, 2003, pp. 119- 144.

${ }^{12}$ VÁZQUEZ MONTALBÁN, M.: Historia y comunicación social. Alianza Editorial. Madrid, 1982, p. 154.

${ }^{13}$ GARCÍA GALINDO, J.A.: "La Historia de la Comunicación Social: algunas propuestas en torno a la investigación científica y la docencia universitaria”, en GÓMEZ MOMPART, J.L. y MARÍN OTTO, E.: Historia del periodismo universal. Madrid, 1999, p.37.
} 


\section{Osuna y su prensa}

A pesar de que el profesor Checa Godoy habla de la existencia de un rotativo nacido en 1851 , no tenemos datos para confirmar su existencia. Asimismo, señala la existencia de tres títulos de los que no se tiene constancia y que son: El Ursaonense, El Cronista y Vida Nueva. El primero de ellos abriría la vida del periodismo local teniendo en cuenta que data su aparición en 1851 y su desaparición en 1852 aunque el nacimiento del periodismo en Osuna se viene situando en 1882 con El Ursaonense, al que también se refiere Checa pero que no muestra como pionero periodístico ${ }^{14}$.

La prensa de Osuna (provincia de Sevilla), tiene su origen a finales del siglo XIX, más concretamente en 1882. No es casual que nos remitamos a los años de la Restauración, etapa que vivió una edad dorada del periodismo gracias a las facilidades de las nuevas leyes y a la paz política. En este contexto, nacía el periódico El Ursaonense. El primer impreso de la ciudad que es creado por un grupo de intelectuales, siendo su fundador Enrique Rodríguez Durán, doctor en matemáticas. Sin embargo, fue, en realidad, Francisco Rodríguez Marín -erudito español nacido en Osuna en 1855, Director de la Biblioteca Nacional que murió en Madrid en 1943- el verdadero director y escritor de todo el periódico.

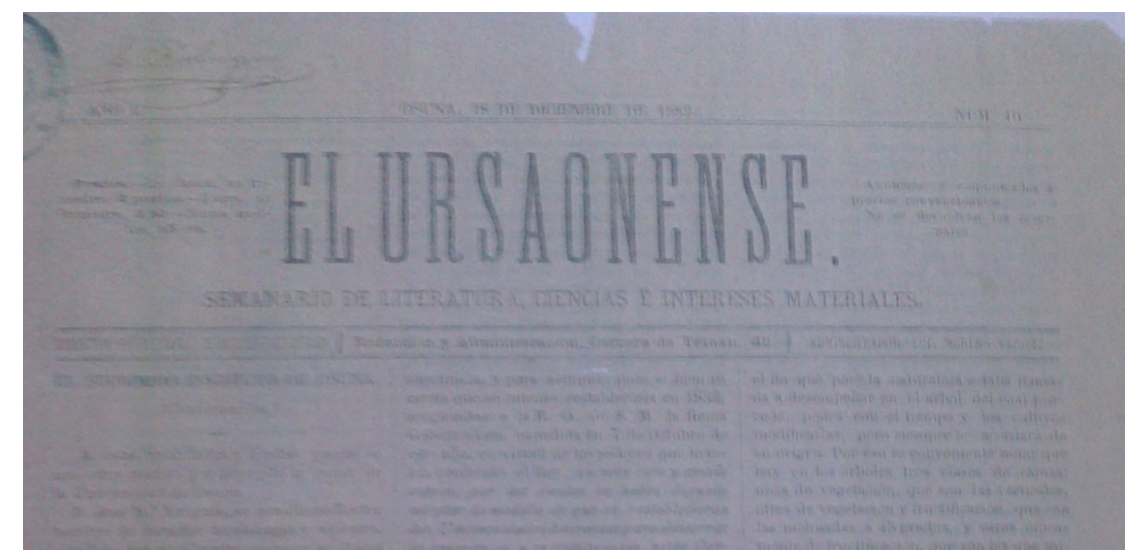

En 1885 El Ursaonense desaparecía y el propio Pascual Recuero ${ }^{15}$ afirmaba que dejó de publicarse como consecuencia de la crisis desatada tras la muerte de Alfonso XII. Aún así, parece ser que la decadencia del periódico ya había comenzado con carácter previo a dicho acontecimiento, achacándose su extinción, más bien, a las influencias e intereses de aquellos a los que el carácter crítico de la publicación no les beneficiaba.

Si en 1885 desaparecía El Ursaonense, el 7 de febrero de 1886 veía la luz El Centinela de Osuna. "Semanario de literatura e intereses morales y materiales" que desaparecerá el 25 de septiembre de 1886. Se publicó los domingos bajo la dirección de

\footnotetext{
${ }^{14}$ CHECA GODOY, A.: Historia de la prensa andaluza. Ediciones Alfar. Sevilla, 2011, p. 360.

${ }^{15}$ PASCUAL RECUERO, P.: “Antonio Mạa García Blanco y el hebraísmo español del S. XIX” Granada, Univer sidad.1986. Página 318 en: RAMÍREZ OLID, J. M.: Osuna durante la Restauración (1875- 1931), p. 608.
} 
Francisco Rodríguez Marín y la administración de Manuel Vela Arjona y se funda como un "[...] un periódico polemista y áspero [... ${ }^{16}$. Asimismo, a fecha 9 de octubre de 1887, Eulogio Jurado Fernández, colega de Rodríguez Marín que también ostentó la dirección del periódico, escribía en una especie de bando que El Centinela había muerto debido a la morosidad de sus suscriptores - el documento en cuestión aparece sellado por el Ayuntamiento Constitucional de Osuna -.

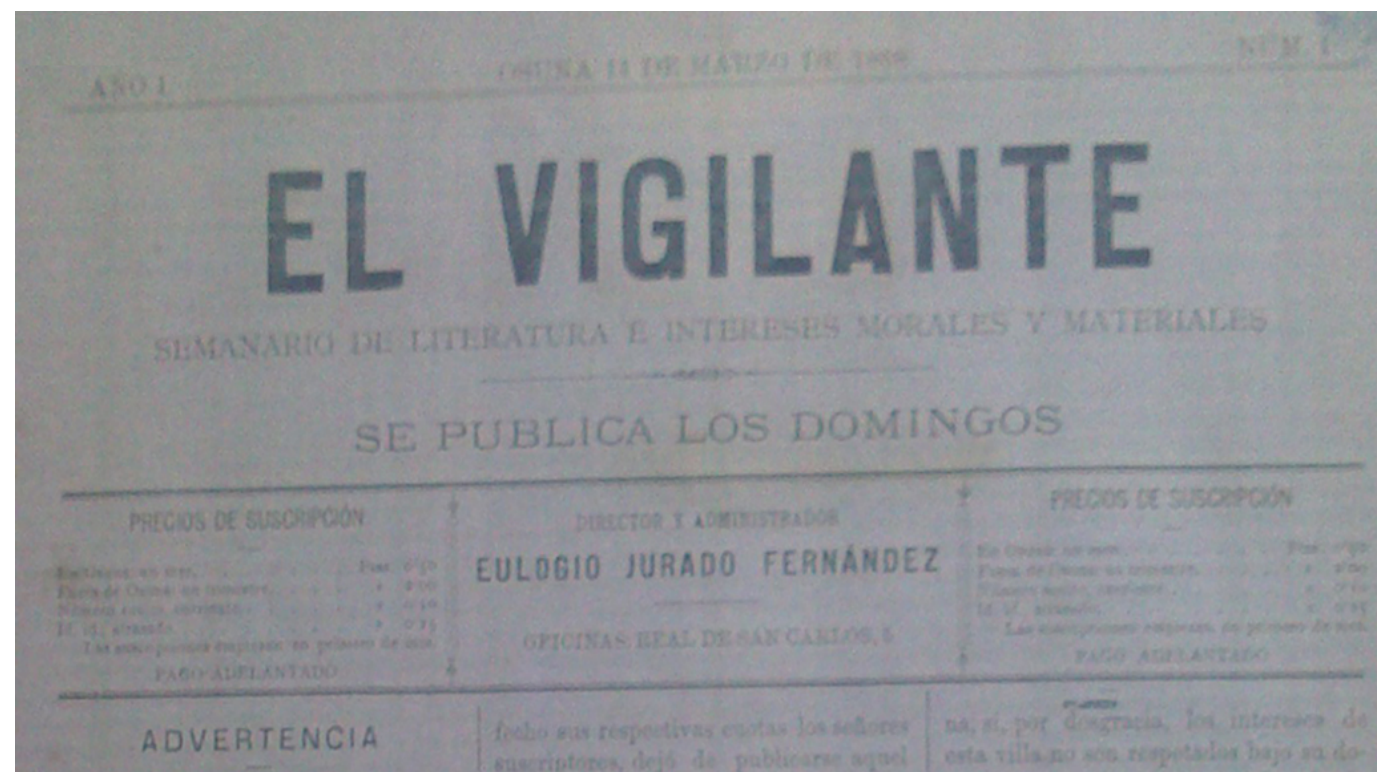

El 11 de marzo de 1888, nace El Vigilante. "Semanario de literatura e intereses morales y materiales". Publicándose los domingos, a partir del 7 de junio de 1888 comenzó a publicarse los jueves mientras que, a partir del 5 de enero de 1989, se publicará seis veces al mes hasta que desaparezca a fecha 31 de mayo de 1889. Se crea bajo la dirección y administración de Eulogio Jurado Fernández, el que será redactor jefe de EI Paleto años más tarde. Precisamente, El Paleto publicaba una necrológica y una carta de despedida en su honor en la portada del 24 de septiembre de 1904.

Hasta la aparición de El Popular en abril de 1893, no podemos dejar de mencionar la creación, el 5 de mayo de 1888, de lo que en principio era una hoja diaria de información y, posteriormente, se convirtió en una publicación trisemanal: Osuna al Día. Será el ursaonés, Álvarez Santaló, quien nos ilumine al respecto y por él sepamos que deja de publicarse un año después cuando afirma: "Se conserva un buen paquete de números de los cuatro años que dura la publicación, aunque muy descabalados. Parece que deja de publicarse en julio de $1892^{17 \prime \prime}$.

\footnotetext{
16 ÁlVAREZ, R., ZAMORA, M. y LEDESMA, F.: La vieja prensa de Osuna y El Paleto $2 \underline{a}$ Época. Fundación se Cultura "García Blanco" del Ayuntamiento de Osuna. Osuna, 2000, p. 25.

${ }^{17}$ RAMíREZ OLID, J. M.: Osuna durante la Restauración: 1875- 1931. Volumen II. Ayuntamiento de Osuna. Osuna, 1999, p. 82.
} 
Atendiendo a lo publicado por Santaló, tenemos conocimiento de un periódico de crítica festiva: El As de Bastos cuyo contenido debió ser bastante crítico ya que, tras varias quejas, el ayuntamiento mandó retirar la edición y su director terminó en la cárcel. Ello explica que su segundo número, a pesar de ver la luz, acabase siendo requisado. Igualmente explica que no se conozcan ejemplares de números posteriores. El propio Santaló también cita otros dos títulos periodísticos: El Liberal y El Combate que, a pesar de aparecer nombrados en El Popular y en Osuna al Día, respectivamente, no existe constancia de su existencia física.

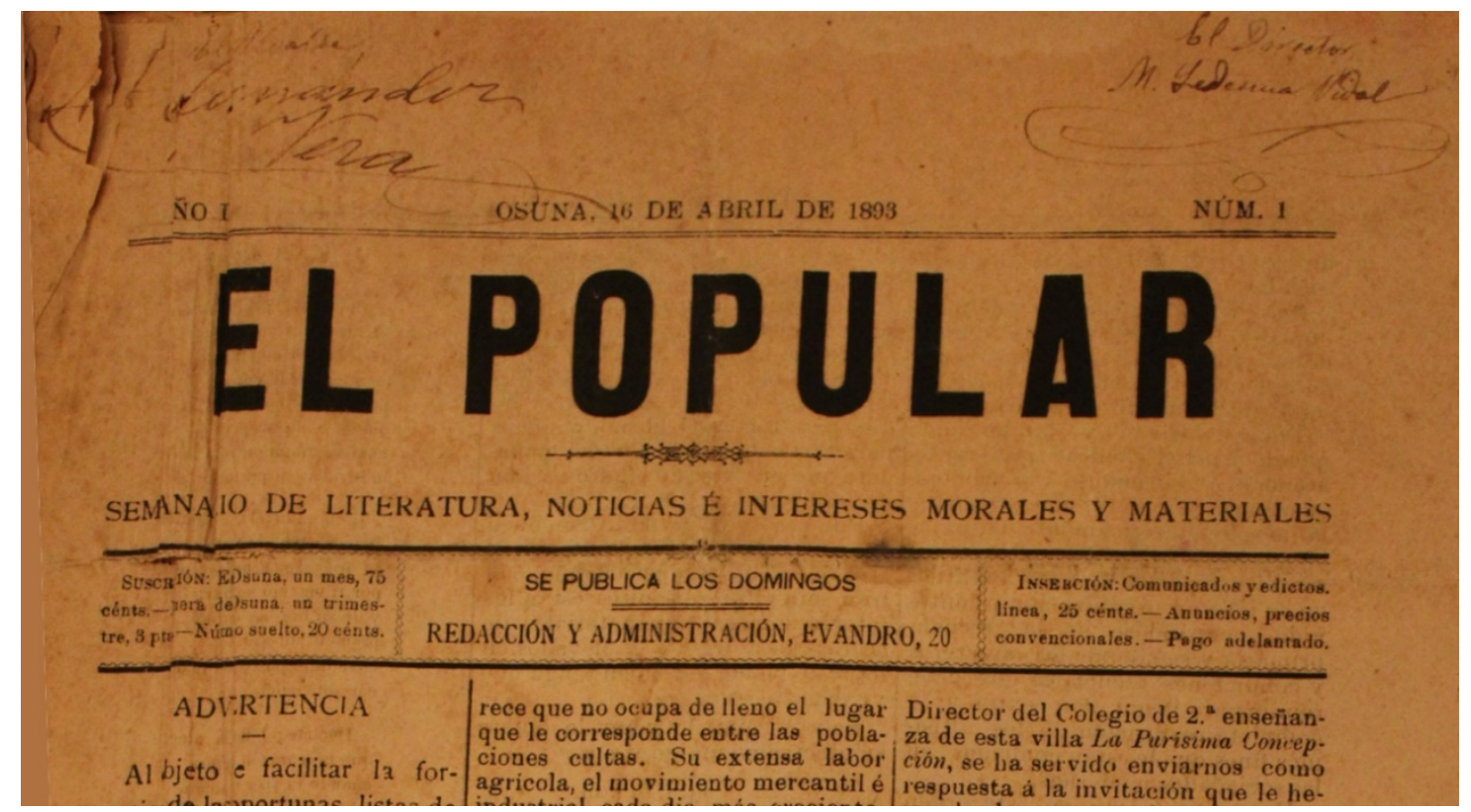

El primer número de El Popular sale a la luz en abril de 1893 hasta que deja de publicarse en septiembre de 1898, definiéndose a sí mismo como "Periódico de literatura, noticias e intereses morales y materiales".

Cuatro años después de su desaparición, en 1902, aparecería El Paleto, coincidiendo en el tiempo con El Labriego. Pocos ejemplares y datos obran en nuestro pode a excepción de su número 10, publicado el 27 de octubre de 1901, localizado en la sala destinada a la prensa del Museo Etnográfico de Osuna.

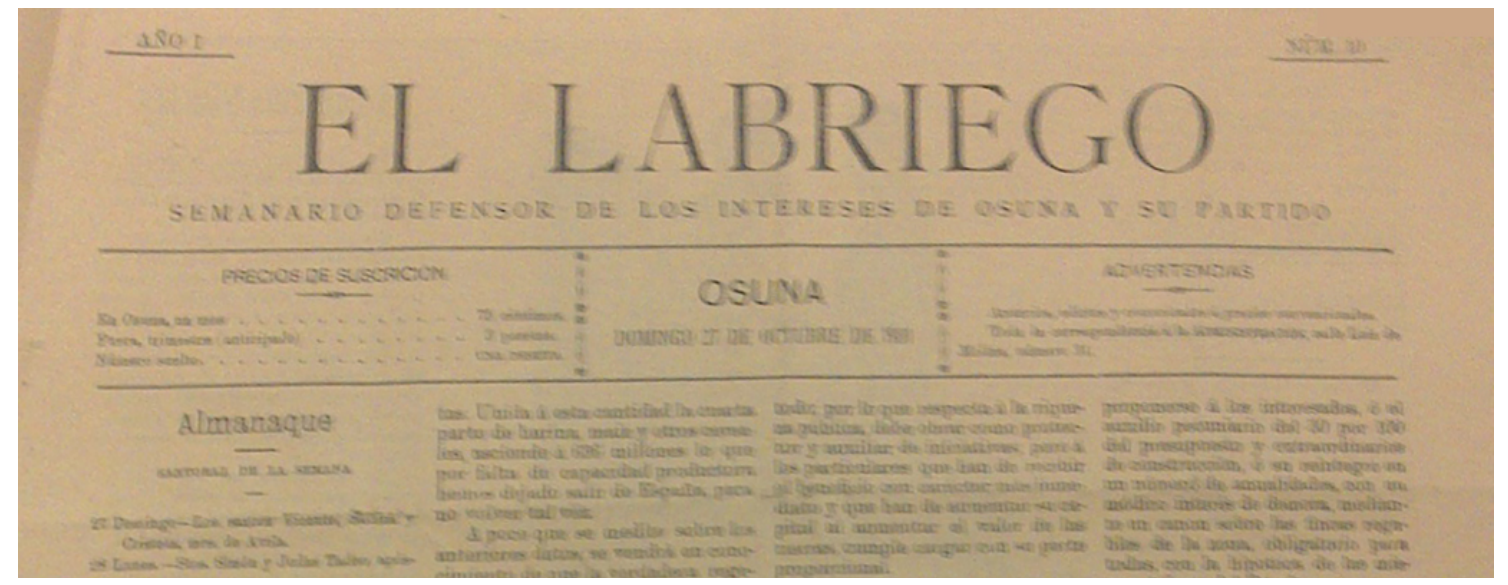


Además de El Paleto, que sería el siguiente en aparecer, localizamos diferentes iniciativas periodísticas durante el tiempo que nuestro objeto de estudio continuó publicándose. El Obrero, creado, también, en 1902, del que solo se conservan el número uno y tres en la colección privada de José Torrejón Real; Humanidad, será la siguiente iniciativa periodística mientras que de La Semana pocos datos existen. Sabemos de él por una referencia en El Paleto que nos hace ver que debió aparecer en los primeros días de abril de 1916. De El Timbre conocemos de su existencia por una carta de Rodríguez Marín al director de El Paleto haciendo ver que su publicación pudo iniciarse a finales de 1917. El Eco de Osuna ve la luz el 1 de octubre de 1922 mostrándose como un periódico semanal independiente de intereses morales y locales que se publicó los domingos. La Voz de Osuna se publica por primera vez el 8 de mayo de 1927 como un "Semanario independiente de interés general" aunque no tuvo una vida larga ya que el último número que se conserva es de fecha 27 de noviembre de 1927. La Razón será el último rotativo que se publique antes de que estalle la Guerra Civil española.

Una vez iniciada la contienda, la labor periodística se paraliza y tendremos que esperar algunos años para volver a ver nuevas ediciones en el municipio, más concretamente a noviembre de 1949 con la creación de El Defensor que dejará de publicarse en junio de 1950. Con la llegada de la democracia, nacerá un nuevo periódico: El Paleto. 2 a Época que, realizando un guiño al pasado, recupera en su cabecera el nombre del periódico más longevo de la localidad. En los años siguientes, hasta la actualidad, diversos serán los títulos que se sucedan en el tiempo hasta llegar a nuestros días: La Gaceta de la comarca Osuna- Estepa, Torre del Agua, Sierra Sur de Sevilla Información o El Pespunte, periódico que se mantiene vigente en la actualidad en su versión digital. 


\section{El Paleto, testigo directo de la historia de España}

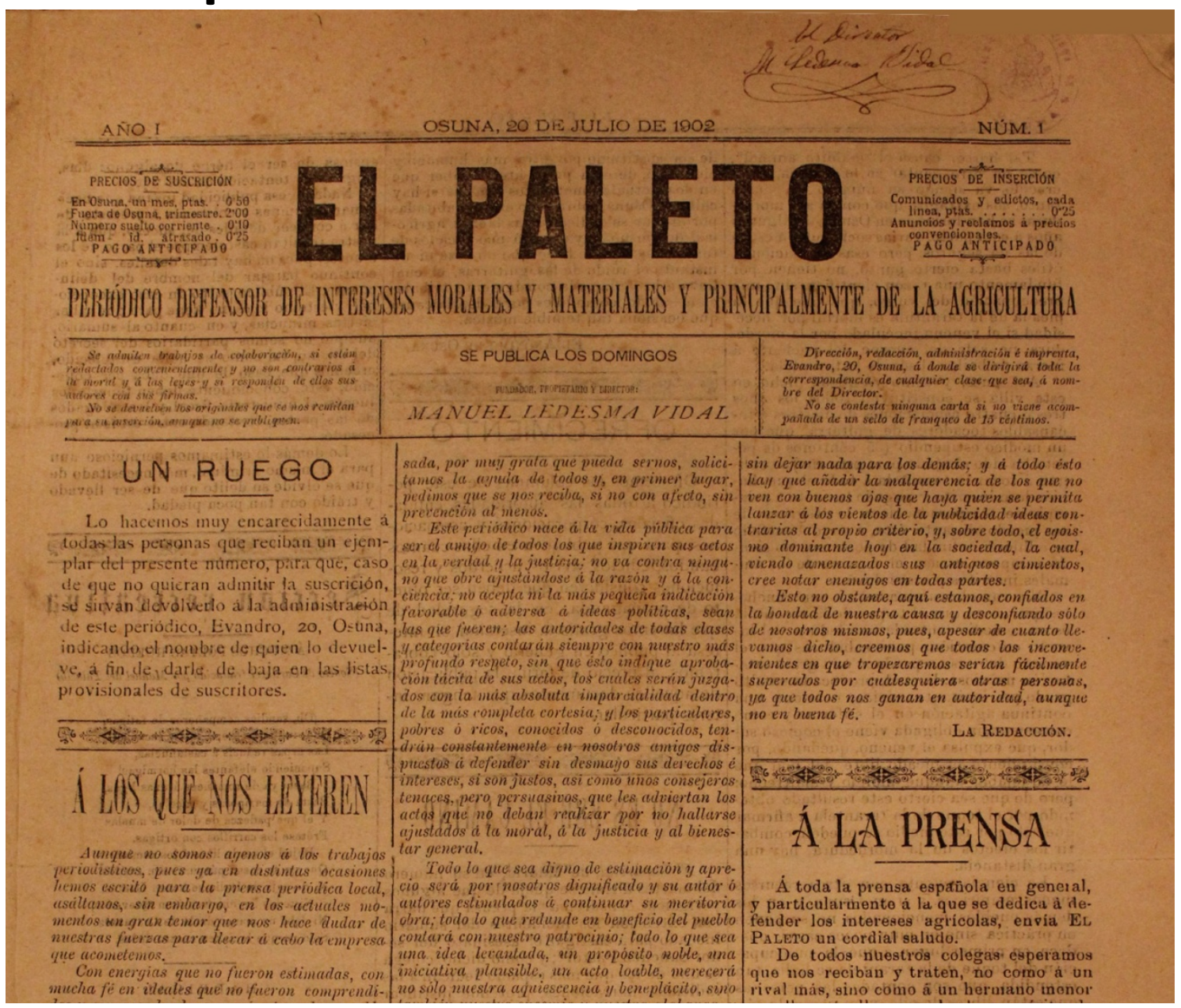

Realizado un breve recorrido por la historia de la prensa en Osuna, nos centramos, a continuación, en nuestro objeto de estudio. El rotativo que más años se publicó en Osuna: treinta y cuatro años, de julio de 1902 a julio de 1936.

Estos datos, a priori, ponen de manifiesto la excepción que supone la existencia de EI Paleto para la historia de la prensa ursaonense así como para la historia del periodismo local de la Restauración, tal y como afirma el profesor Antonio Checa: “[...] No abundan los periódicos duraderos, por la inestabilidad política, tampoco los ingresos publicitarios muestran la generosidad de los años veinte, sin contabilizar revistas religiosas, suponen una veintena de títulos... y otras dos en Sevilla, "La Voz" de Écija y "El Paleto" de Osuna $[\ldots]^{\prime \prime 18}$.

\footnotetext{
${ }^{18}$ RAMÍREZ OLID, J. M.: Osuna durante..., Op. cit., p. 445.
} 


\subsection{Aproximación al objeto de estudio}

El periódico local El Paleto ve la luz de la mano de su creador: Manuel Ledesma Vidal y de su redactor jefe: Eulogio Jurado Fernández, promotores de esta iniciativa periodística que a lo largo de los treinta y cuatro años de su existencia, evolucionará su línea editorial paralelamente a los regímenes políticos que se sucedan durante estos años a nivel nacional: monarquía, dictadura y república.

En los primeros años de vida, El Paleto parece mostrar su lado más crítico al no tener impedimento en arremeter contra el gobierno local en relación a aquellas cuestiones que estima oportuno. Publicaciones que harán peligrar, incluso, la vida de su director que sufrió un atentado contra su persona tras publicar críticas al mal estado de los alimentos en la plaza de abastos. La información al respecto la leemos en la portada del 1 de octubre de 1916 donde, bajo el titular “iComo en el Riff! iAsesinato frustrado!”, el periódico narra cómo un funcionario, tras las acusaciones vertidas, se tomó la justicia por su mano disparando a Ledesma. Una actitud crítica que oscilará dependiendo de si, durante el sistema de turnos, se encuentran en el poder liberales o conservadores, así como si nos encontramos ante el periodo dictatorial o durante el gobierno republicano: "[...] la malquerencia de los que no ven con buenos ojos que haya quien se permita lanzar á [SIC] los vientos de la publicidad ideas contrarias al propio criterio y, sobre todo, el egoísmo [SIC] dominante hoy en la sociedad, la cual, viendo amenazados sus antiguos cimientos, cree notar enemigos en todas partes". (20-7-1902: 1).

Un rotativo, sobre el que, hasta el momento, no se ha podido investigar acerca del público lector que se acercó a su contenido y que abre en su cabecera con la inscripción: "Periódico defensor de intereses morales y materiales y principalmente de agricultura" con una periodicidad semanal que más adelante pasará a editarse cada diez días. Consta de cuatro páginas conformadas por diversas secciones que, distribuidas en tres columnas, tratan temáticas que, a nivel local, provincial, regional, nacional e incluso internacional, afectan a Osuna siendo, en su mayoría, asuntos relacionados con el mundo de la agricultura así como de la economía en general o del trabajo realizado por los políticos. La portada, en este periódico de formato tabloide, suele destinarse a acoger artículos de fondo mientras que en la segunda y tercera página encontramos la "Sección recreativa”, "Ayuntamiento", "Noticias" o "Conocimientos útiles", entre otras. Finalmente, la cuarta y última página se destina, a página completa, a insertar publicidad a pesar de que existe la posibilidad de encontrar anuncios en la tercera y a partir de 1912 será habitual localizarlos en todas las páginas del rotativo. 


\subsection{Temas centrales en El Paleto durante el reinado de Alfonso XIII}

A finales del siglo XIX tenía lugar la pérdida de la tutela de la casa de Osuna. Consecuentemente, Osuna pasa a ser una ciudad provinciana que basó su economía en la agricultura. Cuando comienza el siglo XX, la localidad se encontraba bien insertada en el sistema de la Restauración reproduciéndose en la política municipal el turnismo del gobierno de Estado. Los dos grandes partidos que se van a disputar la alcaldía de Osuna - reflejando la realidad nacional a nivel local -van a ser cómplices del sistema turnista que hará del caciquismo su principal arma para conseguir sus objetivos.

El inicio del periodo monárquico protagonizado por el rey Alfonso XIII viene a coincidir, prácticamente en el tiempo, con el nacimiento de El Paleto, el cual comenzará su andadura en el mes de junio de 1902. Nuestro objeto de estudio va a ver la luz en el momento en el que se encuentra gobernando el Partido Liberal con Francisco Domínguez Fernández regentando la alcaldía de Osuna ${ }^{19}$. Puesto político esencial en la Restauración a nivel local para poder controlar la trama caciquil que maneja los hilos del poder desde lo local hasta lo nacional. Al alcalde le importa, por encima de todo, conseguir los objetivos marcados por el sistema imperante: el turnismo. Para ello, recurrirá a la manipulación electoral - el denominado pucherazo - utilizada durante la Restauración con el fin de permitir la alternancia en el poder. En Osuna, tuvieron lugar, durante estos años, un total de treinta y siete cambios en la alcaldía, repitiendo alguno en dos ocasiones y tres en algunos casos. Una figura, la del alcalde, a la que el historiador local Ramírez Olid se refiere del siguiente modo:

Los alcaldes, pues, hacen las listas electorales, incluyen y excluyen electores a su conveniencia, reparten las cédulas y los consumos, utilizan los impuestos como premio o como castigo, burlan la ley para los amigos y la aplican con rigor a los enemigos. En definitiva, en los medios rurales el alcalde es un tiranuelo que interpreta la ley según conviene y la trasgrede cuando es necesario con la anuencia de sus superiores. [...] Por ello, la administración municipal, esté en manos de quien esté, seguirá igual, rutinaria, sin solucionar problemas que por su duración se convierten en endémicos, parcheando inconvenientes para salir del paso, porque el alcalde no es designado por sus cualidades para administrar el municipio, sino por sus habilidades electorales y su docilidad con el cacique. Así, cuando se produce un cambio de partido en el gobierno, inmediatamente se procede a nombrar un alcalde interino del partido entrante para que prepare las elecciones en su localidad ${ }^{20}$.

\footnotetext{
${ }^{19}$ RAMÍREZ OLID, J. M.: Osuna durante..., Op. cit., p. 378.

${ }^{20}$ Ibídem, p. 218.
} 
De este modo, se fueron sucediendo diferentes personalidades en la alcaldía de la localidad durante los primeros años en los que vio la luz EI Paleto y que, como veremos más adelante, tendrán su reflejo en el contenido de sus páginas. Siendo una localidad eminentemente agrícola en la que la situación del campo influirá en todos los aspectos de su vida cotidiana. Todo ello unido a una mentalidad un tanto arcaica, explica que los ursaonenses de finales del siglo XIX se muestren reacios a las innovaciones técnicas que para el campo se iban poniendo en marcha en otros lugares del país e incluso de la propia provincia. Cuestiones estas que nos pueden ayudar a comprobar por qué las primeras noticias relacionadas con la gestión política local - y/ o nacional- mostrarán su cara más crítica.

De este modo, y tras abordar el estudio del contenido de ejemplares publicados durante la etapa de la Restauración - teniendo en cuenta la falta de fondos en algunos años de la que ya hablábamos anteriormente - nos encontramos con que los temas que más importancia van a tener para El Paleto serán los siguientes:

- En primer lugar, señalamos las referencias a la política local como uno de los temas que más espacio va a ocupar en el rotativo. En esta ocasión, hemos valorado tanto las críticas como los aplausos que recibieron los diferentes gobiernos que se sucedieron en Osuna desde 1902 a 1923. Llama la atención que la mayoría de críticas a la gestión local se sitúan en periodos liberales: 1903 con 17 artículos al respecto, por ejemplo, mientras que los aplausos se concentran en periodos conservadores, tal y como ocurre en 1914 con 15 publicaciones y 1915 con 16. Dato que, a priori, nos va a dar una información muy valiosa para catalogar a El Paleto en lo que a su ideología y postura adoptada sobre los acontecimientos históricos de los que se hará eco.

Muestra de ello será, entre otros, el artículo que, en la portada del 24 de mayo de 1903, se publica bajo el titular "SURGE ET AMBULA":

Sí, Ayuntamiento de Osuna, nuevo Lázaro: surge et ambula, levántate y anda, porque es necesario, porque es imprescindible que te levantes del sepulcro de la inacción en que yaces como un cadáver, para que contigo se levante nuestro pueblo, que está muerto, que está putrefacto; porque es preciso, porque es indispensable que andes por el camino de la verdad y de la vida para que osuna marche á [SIC] su vez por la senda del progreso y de la cultura. Basta ya de incuria, basta ya de inacción y de injusticia, y de sin razón, y de favoritismo, y de compadrazgo, y de considerar los cargos concejiles como un medio de satisfacer ambiciones, y desafueros de sus administradores. Hay que cambiar de método y de sistema y de conducta, y hacer todo lo contrario de lo que se ha hecho hasta ahora. Nuestro pueblo está necesitado de administración buena, honrada, leal y económica; por su precario estado reclama á [SIC] todo trance que se cultiven sus intereses morales y materiales, fomentando para ello todo lo que represente educación y cultura y haciendo que puedan desarrollarse, debidamente sus 
distintos ramos de producción agrícola é [SIC] industrial; y también hay que higienizarla [...] Para lo malo, para lo inútil, para lo pequeño, para lo perjudicial, no hacen falta cambios políticos y bien puede el pueblo pasarse sin ellos. Para que no se continúe por ese camino, terminamos este artículo dirigiendo al futuro Ayuntamiento el mandato que nos sirve de epígrafe: surge et ambula.

Tres semanas escasas más tarde, el 14 de junio de 1903 y en primera página, encontraremos "PERDÓNALOS, SEÑOR". En esta ocasión los políticos vuelven a ser blanco de las críticas de El Paleto pero como consecuencia de las opiniones que están divulgando en contra de la labor periodística:

Para admiración de ignorantes, espanto de pusilánimes y conmiseración de espíritus cultos y sensatos, tenemos actualmente en Osuna varios políticos de avanzadas ideas que han puesto cátedra de crítica periodística, y da gusto oírles hablar de la prensa y de los que ésta escriben. Ellos no sabrán lo que es libertad, ni democracia, ni república, ni socialismo, ni anarquismo; pero, en cambio, tienen por seguro é $[\mathrm{SIC}]$ indudable que está vendido al oro de la reacción todo periódico y todo periodista que no llame zotes á [SIC] los ministros, poncios á [SIC] los gobernadores, caciques á [SIC] los jefes de partido, calabazas á [SIC] los senadores y diputados [...] nada les importa á [SIC] ellos que, un periódico usando palabras cultas y razones convincentes, venga un día y otro día [...] combatiendo toda clase de inmoralidades é [SIC] injusticias, pidiendo reformas beneficiosas, [...] Aprendieron política en el diccionario de los insultos [...] Lo que seduce a esos políticos no son los pensamientos, sino las palabras gruesas; no son las exquisiteces del bien decir, sino las acritudes del lenguaje; no son las dulzuras de la cortesía, sino las hieles de la enemistad. Con tales gustos y tales tendencias, no es extraño que se dediquen a desconceptuar todo escrito, por muy justo y razonado que sea [...] Por tal razón, cuando tenemos noticias de las críticas de esos críticos, como se nos alcanza bien que desconocen el daño que ocasionan, no podemos menos que decir con Jesucristo: perdónalos, Señor, que no saben lo que hacen.

Los problemas que surgen en el municipio con respecto al abastecimiento de agua, los caminos vecinales o el control del peso del pan, entre otros, serán algunos de los temas que den forma a las críticas que localizaremos en este periodo. Con respecto a los aplausos a la política local localizamos, entre otras: "El sentir de un pueblo", publicado en la segunda y tercera página del número de 5 de marzo de 1914, donde se hace referencia al diputado conservador a Cortes, Don Cristóbal de la Puerta. Se trataba del cacique conservador de Osuna al que el periódico exalta. Cristóbal de la Puerta será el protagonista de otras publicaciones. Esto ocurrirá una semana más tarde cuando, al publicarse en la portada del 12 de marzo de 1904 "En vías de regeneración", se muestre la alegría tras conocerse la victoria del diputado a Cortes: "porque el pueblo ha sabido 
elegir". Escasas tres semanas después, en la portada del número del 5 de abril de 1914, el alcalde conservador, Rafael de Soto Torres- Linero será el protagonista en "iLoado sea el buen deseo!". El rotativo aplaude las acciones llevadas a cabo por el primer edil en contra de los malos hábitos de higiene en la villa.

- La política nacional también ocupa un peso importante en las publicaciones del rotativo, destacando la crisis del sistema y el caciquismo. Encontramos referencias al caciquismo, entre otros, en las portadas de los números del 11 y 18 de octubre de 1917 mediante el titular "Vida local". En el primer número se crítica la involución a la que Osuna está sometida y donde se pone de manifiesto el lamentable papel que los "los constituidos en directores de un pueblo" llevan a cabo. En el segundo, se finaliza el artículo reproduciendo una historieta de un "Cacique máximo: don Restituto Estirado, de Chupamelona de Abajo" y los grandes halagos que conseguía. Por su parte, llegando al fin del periodo monárquico, El Paleto publicaba en la portada del 20 de diciembre de 1922: "...Y así seguimos decayendo":

Sí; lo mismo en las aldeas, pequeñas e insignificantes, que en las poblaciones más grandes y populosas, el político de oficio representa para los incautos, para los confiados, eterna e idéntica comedia. Iguales escenas se ofrecen al observador; escenas de un convencionalismo cómico, a veces, en la apariencia y trágico en el fondo, que sin cesar se reproducen y cuyos resultados son siempre fatales para el país. En la oposición, el político es el redentor que viene a librarnos del yugo tiránico que nos oprime y aniquila, y a sacarnos, pese a quien pese del abismo en que nos arrojaron la maldad o la ineptitud de torpes y malos estadistas. En el poder, se olvida del o que predicó, de sus buenos propósitos, y lo que antes era tenido por él domo el colmo de las torpezas, del desconcierto y del desbarajuste, se convierte entonces por desconocido encantamiento, en pruebas de acierto, de orden, y de buena administración para conseguir, por iguales procedimientos, el engrandecimiento patrio [...] Es, por desgracia, tan cierto esto, que sin duda, envuelto y cegado por las irradiaciones emanadas de ese poder que satisface sus ambiciosos anhelos, y ensoberbecido por la elevada posición que ocupa, no se da cuenta exacta, ni se apercibe ia tanto llega la vanidad satisfecha! De lo distanciado que se halla del público sentir. Y embebido y encantado, además, con los sonoros periodos de sus rimbombantes y artificiosos discursos, a sí mismo se deslumbra, viéndolo todo a través de rosados prismas que disfrazan y ocultan lo falso y tenebroso de la situación que le rodea, ocurriéndole lo que a los grandes embusteros: que llegan a creerse sus embustes, a fuerza de repetirlos..., puesto que vemos en contraposición el dicho con el hecho; nos prometen reformas a montones, beneficios sin cuento; todos nos traen el único y exclusivo remedio, la panacea universal, y remedando a los más osados sacamuelas, pregonan a voz en grito la bondad, lo infalible de sus sistemas, y proclaman en todos los tonos la extirpación de las corruptazas, la regeneración del país. Mas, a pesar de los 
desengaños sufridos, que debían servir de saludable lección y de beneficiosa enseñanza, existen innumerables inocentes, infinitos incautos, que escuchan con la boca abierta a esos políticos de oficio, igual que la gente ignorante oye a los charlatanes de plazuela... Y así seguimos decayendo, atraídos [SIC], envueltos por tantas promesas que no se cumplen, por tantas vanas palabras que el viento se lleva.

- Otros asuntos como el regeneracionismo, las ideas regionalistas, el patriotismo, el conservadurismo retrógrado, la religión o la oposición a las huelgas y las izquierdas serán protagonistas entre las páginas de nuestro objeto de estudio.

Dentro de las ideas regeneracionistas, destaca, desde los primeros meses de vida del rotativo, la oposición a la construcción de una plaza de toros. Esta cuestión se observa, entre otros, en la portada del 21 de septiembre de 1902 con el artículo titulado: “¡EH, Á [SIC] LA PLAZA!":

[...] Bien; no me meteré á [SIC] censurar el espectáculo llamado nacional, no por temor de que me traten de cursi, que esto me importaría poco si hubiera de lograr mi objeto de impedir la construcción del circo en proyecto; pero sí diré que esa fiesta no proporciona ninguna ventaja á [SIC] los pueblos. Hágase, pues, la plaza si así es la voluntad de los que la desean; pero como parece que se cuenta con la cooperación del Ayuntamiento para que ceda el terreno y además subvencione á [SIC] la empresa constructora, hay que oponerse á [SIC] esto, porque el Ayuntamiento, antes que ceder ese terreno para una obra que no dará ilustración ni, probablemente, utilidad, debe pensar en algo que sea más beneficioso; y primero que dar dinero para la plaza de toros, debe pensar en pagar lo mucho que debe. Yo acabe, por hoy. ¿Quién quiere tomar la alternativa?

Asimismo, la regeneración de los pueblos, también ocupará su lugar en la portada del 26 de octubre de 1902 con el titular "Pueblos y poblachos" donde se sitúa a Osuna en el segundo caso. Otro asunto que ocupó varias páginas del periódico, a partir de 1903, fue la constitución de una comunidad de labradores así como las cuestiones relacionadas con la cultura y la educación. Temática esta última que dio forma a "Respetemos al maestro" al publicarse en la portada del 28 de noviembre de 1912:

[...] La prosperidad y gloria de las naciones al maestro se deben [...] los ciudadanos libres, honrados, inteligentes, activos y trabajadores por la escuela y bajo la influencia y cuidados del educador han de pasar. - No existe otro mal que la ignorancia, ni otro bien que la ciencia - decía Sócrates. Si queréis ser instruidos y aumentar vuestra felicidad, reconciliaos con el maestro, acudid a la escuela.

"La esclavitud de los que mandan" (1911- 10- 19: 1), "La reforma del reclutamiento" (1911- 10- 19: 2), “De elecciones" o “Agricultores, ia europeizarse!” (1916- 07- 06: 1) 
son, entre muchos otros, algunos de los titulares que mostrarán las ideas regeneracionistas del periódico.

Los artículos que hacen alusión al patriotismo comienzan a insertarse durante los años de la Primera Guerra Mundial siendo el primer titular "De la escuela militar" (1914- 0326: 1), "Fiesta de la raza iberoamericana" (1915- 09- 30: 2), "Así se sirve y se honra" (1916-08- 03: 1) o "Símbolos" (1923- 07- 20: 1), entre otros.

El conservadurismo retrógrado también será protagonista entre 1914 y 1922 con artículos como el que lleva por título "El carnaval" (1917- 07- 22) o "Feminismo" (192208- 20), entre otros, junto a la religión católica, hacia la que el rotativo mostrará su apoyo frente a la oposición a las huelgas y las ideologías de izquierdas. Sobre el primer caso destacan “¿Quién hizo el monte?" (1915- 03- 11: 1), "Lo infinitamente pequeño" (1916- 11- 23: 1) o "Las iglesias de Italia" (1922- 07- 31: 1). La oposición a huelgas y las izquierdas se reflejará en "No es societario, es anarquista" (1915- 01- 07: 1) o “¿De dónde viene la perturbación?" (1920-12- 6: 1), entre otros titulares.

\subsection{Temas centrales en El Paleto durante la dictadura de Primo de Rivera}

El periodo monárquico de la Restauración llegaba a su fin y con él se establecía la dictadura de Primo de Rivera. Una noticia que, al parecer, fue tomada con alegría y entusiasmo entre los ursaonenses al contrario de lo que ocurrió a la muerte del dictador $^{21}$. Comenzaba una nueva etapa con la que se pretendía poner fin a los abusos y malas gestiones que habían caracterizado el periodo anterior:

Una de las primeras medidas del Directorio militar fue la sustitución de los gobernadores civiles por gobernadores militares. Ello le permitía a Primo eliminar de un golpe en un cargo tan importante en el entramado caciquil a todos los políticos liberales [...] Empieza, pues, lo que González Calbet ha llamado la etapa destructiva de la Dictadura $[\ldots]^{22}$.

Insertos en plena Dictadura y en las directrices que se establecieron, comenzaba la "lucha" contra el caciquismo a nivel legislativo aunque, siguiendo a autores como

\footnotetext{
${ }^{21}$ La noticia de su muerte en el exilio el 16 de marzo de 1930 en París, fue tomada con cierta frialdad por parte de las autoridades a pesar de que, finalmente, la corporación municipal decidiera incluir en acta, al final de una sesión permanente celebrada días después del fallecimiento, el sentimiento en nombre del pueblo por la muerte del Excmo. Sr. D. Miguel Primo de Rivera.
}

${ }^{22}$ RAMÍREZ OLID, J.M.: Osuna durante..., Op. cit., p. 419. 
González Calbet, ello no fue óbice para que algunos delegados gubernativos se convirtieran en auténticos caciques ${ }^{23}$.

A pesar de que las actuaciones del dictador, hasta el momento, se habían saldado con éxito, a finales de 1925 se creará el Directorio Civil y será a partir de entonces cuando empiecen los problemas de Primo de Rivera que encaminará su mandato a su ocaso. De hecho, en el periodo transitorio que se abre tras la marcha de Primo de Rivera, que algunos autores denominan dictablanda, se produce en Osuna una huelga de clara intencionalidad política que nos confirma que la localidad no estuvo ajena a los vaivenes de la política nacional:

En 1930 los obreros del campo convocaron una huelga esencialmente política, pues no existe una plataforma reivindicativa, ni responde a deseos de mejoras sociales, sino únicamente a contribuir al desasosiego y desestabilización política a raiz [...] de las sublevaciones de Jaca y Cuatro Vientos. En efecto, el 12 de diciembre se produce la sublevación en Jaca y tres días después la de Cuatro Vientos, e inmediatamente los obreros del campo se ponen de huelga, alentados por anarquistas y marxistas que los ilusionan con el reparto de fincas. La duración es muy corta y de escasa incidencia [...] El 18 de diciembre volvieron al trabajo muchos jornaleros y el 19 se reanudaron las actividades con toda normalidad ${ }^{24}$.

Ante el nuevo cambio de gobierno, El Paleto del día 20 de septiembre va a acoger en su segunda página la noticia de lo que está por venir en el país y que va a prolongarse durante los siguientes siete años. Así informó El Paleto del comienzo de la dictadura de Primo de Rivera en el artículo "Un gobierno de generales": "Aceptada por el Rey la provisional forma de Gobierno nacida del acto realizado en Barcelona por el general Primo de Rivera, la primera medida fue declarar el estado de guerra en toda la Nación. En su consecuencia, y llegadas a Osuna las órdenes oficiales, el domingo se les dió [SIC] publicidad mediante la fijación del siguiente Bando [...]".

Nos adentramos en un periodo histórico en el que podemos agrupar las temáticas que darán forma al contenido publicado en El Paleto en los siguientes bloques: La dictadura y sus representantes, el patriotismo, el caciquismo y la exaltación de la educación y los valores vistos desde un punto de vista regeneracionista, la crítica a las fiestas populares - tema tradicional en el rotativo - y, por último, crítica a la situación de la mujer ante la política.

Sendos ejemplos localizamos en relación al primer bloque temático, tal y como ocurre con "El nuevo delegado gubernativo", publicado en la tercera página del número de 20 de marzo de 1924:

\footnotetext{
${ }^{23}$ RAMÍREZ OLID, J.M.: Osuna durante..., op. cit., p. 423.

${ }^{24}$ Ibídem, pp. 162- 164.
} 
[...] este señor se nos ha revelado gran patriota y, como tal, dispuesto a robustecer el imperio de la Justicia, a desterrar antiguas corruptelas, a curarnos de perniciosos vicios y costumbres y a imponer, [...], hábitos saludables que nos conduzcan derechamente, por estímulo propio y noble aspiración, a ser incorporados en el número de los pueblos sanos, cultos y bien organizados [...].

En portada de fecha 20 de junio, se publica "Cámara oficial agrícola de la provincia de Sevilla" donde se elogia la labor de Primo de Rivera y el Directorio Militar:

[...] Y esa esperanza redentora se manifiesta con caracteres vigorosos ante el movimiento regenerador iniciado con tanto brío como patriotismo por el Directorio Militar, que recoge en su bandera la solución del problema agrario de España, que es el más trascendente de cuantos están planteados dentro de la economía nacional, como lo ha patentizado por el modo elocuentísimo el ilustre patricio Don Miguel Primo de Rivera, [...] en frases tan expresivas como sinceras que corroboran el amor y entusiasmo que resplandecen en el Directorio Militar por todo cuanto afecta al engrandecimiento de la riqueza de nuestro país [...]

O, entre otros, la publicación el 20 de octubre de 1924, en primera, de "El problema de los pueblos":

[...] Los pueblos españoles sufrían, con la jobiana paciencia que es proverbial en nosotros para con nosotros mismos, un buen número de problemas que, cual bandada de siniestros buitres, cerníanse sobre ellos entristeciéndoles funerariamente el sol de su vida y acechando el instante oportuno para destrozarles las entrañas, [...] Nuevos israelitas, soportaban el cautiverio de los faraones de la vieja política soñando a todas horas con el nuevo Moisés que los condujera [...] Decían, y aún dicen que la siniestra madre del lamentable estado de los pueblos españoles era el odioso Caciquismo que, en comandita con su depravada esposa la Vieja Política, exhausta, seca, infecundiza [...] Era preciso, si queríamos salvarnos, acabar de una vez con tan funesto matrimonio. Y para eso, según múltiples declaraciones oficiales, surgió el Directorio Militar, nuevo Moisés que habría de llevarnos a una nueva Tierra de Promisión [...]

Continuando con su labor de reconocimiento al Directorio Militar, en la portada del 31 de julio de 1927 encontramos "Hacia otra Osuna. Dos fechas memorables en nuestra historia contemporánea":

[...] Osuna ha sido, ciertamente, uno de los pueblos que más ha prosperado - y seguirá prosperando - al calor de las circunstancias y de la buena y honrada voluntad de los administradores que nos trajo el histórico gesto del general Primo de Rivera, puesto que todos los ayuntamientos que hemos tenido desde entonces a la fecha no se han dormido en los laureles, si bien el mayor éxito se lo tenían reservado las circunstancias a la recta y constante voluntad del que actualmente 
nos rige presidido por el joven abogado don Antonio de Castro Tamayo [...] En el reinado de este Ayuntamiento hemos tenido los buenos osuneses la satisfacción de ver dos fechas que serán memorables en nuestra historia local...: la creación del Instituto de Osuna y la velada literaria musical del Centro filarmónico en el Casino de Osuna (como se ha vuelto a hacer ahora en unos días nuevamente).

De este modo, se sucederán los contenidos en los que se ensalzará el periodo dictatorial y a sus representantes así como se realizarán alusiones al patriotismo. En cuanto a las críticas vertidas a las fiestas populares y al papel de la mujer en política destacamos, entre otros, los siguientes:

Son los carnavales parte del cliché donde se graba la cultura de un pueblo, que fácilmente se revela allí donde la gente bullanguera se reúne [SIC] [...] ¿No podríamos, teniendo por ciertas las consideraciones expuestas, suavizar tan dolorosa perspectiva restando al carnaval el aspecto chabacano que sólo por empirismo conserva? $[\ldots]^{25}$.

Asimismo, la temática taurina, tras años sin aparecer y habiendo copado numerosos titulares en los primeros números de El Paleto, vuelve a dar forma a uno de los artículos que se publicarán durante la dictadura de Primo de Rivera:

Nuestra fatalidad dispuso que las corridas de toros sean las que en nuestro país influyan soberanamente en el trasiego de masas humanas ávidas de emociones [...] $Y$ en tanto la cultura no evolucione hacia más exquisitos recreos, económicamente pensando hay que transigir con la mal llamada "fiesta nacional", so pena de que las ferias languidezcan y acaben por desaparecer [...] es este un tema sobre el cual todos los años nos permitimos dar un toque de atención, con la esperanza de ser escuchados algún día, persuadidos como estamos de que, para contrarrestar la paulatina extinción de nuestra feria, hay necesidad de vigorizarla acudiendo a otros espectáculos de más modernidad, de más hondo interés, enseñanza y provecho $[\ldots]^{26}$

Finalmente, la mujer también tuvo su espacio entre las páginas del rotativo pero no desde un punto de vista progresista, precisamente, afirmando, en este caso, que la mujer no estaba:

[...] en condiciones de regir por sí sola, ni tal vez acompañada, los destinos del país, con plenas facultades como persona versada en tan intrincada materia, no, porque

\footnotetext{
25 "Tradiciones" (02 de marzo de 1924). El Paleto, p. 1.

26 “De la Feria” (20 de mayo de 1927). El Paleto, p. 2.
} 
carece de la preparación adecuada y la libertad de costumbres que tienen en otros pueblos $[\ldots]^{27}$

\subsection{Temas centrales en EI Paleto durante la II República}

Tras la celebración de elecciones municipales, comenzaba el 14 de abril de 1931 una nueva etapa en España. En Osuna, la noticia de la proclamación de la República se conoce el mismo día:

En Osuna la candidatura monárquica había conseguido el 95 por ciento de los puestos municipales, mientras que en la totalidad de España, incluidas las grandes capitales donde habían ganado las candidaturas republicano- socialista, los monárquicos alcanzaron el 79 por ciento de los puestos. Los republicanos, conscientes de su éxito en casi todas las capitales de provincias y sabedores de que en los pueblos el voto no era moralmente válido por el peso del caciquismo, se atribuyeron inmediatamente el triunfo.

Al poco de proclamarse la República, se realizaron movimientos para intentar conseguir un Estatuto de Autonomía como el que los vascos y catalanes estaban buscando. En ese contexto se dio un hecho muy singular que fue conocido como los sucesos de Tablada. En Osuna, el descontento generalizado, se traducía en las continuas agitaciones que azotaron a la localidad y a la comarca a la vez que el paro seguía siendo preocupante y eso no hacía más que empeorar la situación.

Esta nueva etapa histórica que tendrá su reflejo en las páginas del rotativo tal y como se ve en la portada del número de 20 de abril de 1931 en la que se publica: "Cambio de régimen. Proclamación de la República. Lista del gobierno provisional. Estatuto jurídico del Gobierno". Iniciada la nueva era política, el periódico se limita a dar información en su portada pero no parece mostrar gran ilusión por el nuevo régimen impuesto. De hecho, sus comentarios resaltando la forma en la que Alfonso XIII había procedido para poner fin a su mandato y dar paso al nuevo régimen, valorando el gesto, evidencian sin disimulo su preferencia por el rey:

Ante el adverso resultado obtenido en la mayoría de las capitales de provincia por los candidatos monárquicos en las elecciones municipales celebradas el día 12 del mes actual, el Gobierno de la Monarquía aconsejó prudentemente y el rey don Alfonso, dando ejemplarísima prueba de verdadero patriotismo y correspondiendo noble y fielmente a los deberes que su conciencia le imponía, resolvió facilitar con su inmediata salida de España la proclamación del régimen

\footnotetext{
27 "El voto de la mujer" (10 de octubre de 1924). El Paleto, p. 2.
} 
republicano cuyo ambiente aspiraba el pueblo. Allanando el camino tan caballerosa y pacíficamente, todos los españoles debemos felicitarnos por la forma evolutiva como se ha operado en nuestra Patria el siempre arriesgado tránsito de un régimen secular a otro nuevo en todos los pueblos y colectividades $[\ldots]$.

Inmersos de lleno en la II República española, veremos cómo, además de temáticas propiamente municipales y de interés y origen local, la realidad nacional va a tener cabida entre las páginas del rotativo como reflejo del contexto del momento. Entre las críticas a las reformas de la República se encuentra la relacionada con la reforma agraria, una de las prioridades del gobierno provisional republicano que asustó a los más conservadores entre los que se encuentra El Paleto. Crítica al "enchufismo" o a los nacionalismos que, a ojos del rotativo, están dividiendo el país, serán otras de las temáticas que cuestionará el periódico al nuevo gobierno.

[...] Y los gobernantes, como siempre, impasibles. Ahora le ha tocado a lo que es sustento de millones de españoles. La agricultura está hecha una lástima. Y el ministro del ramo, con todos mis respetos, como un romántico del agro que es, soñando en una Reforma Agraria. [...] Los que dicen “iMuera España!”, los catalanes, continúan explotándonos, a los andaluces más que a otros; y los nacionalistas vascos luchan por la separación de la patria madre. ¿Cuándo terminará este estado de cosas? [...] y el Gobierno [...] itan tranquilo! Es preciso pensar en España. La patria ante todo. [...] Que el Gobierno de la República adopte otra postura con nosotros y con todos. Que la paz y la fraternidad reinen en todas partes. Que se hagan las cosas por su verdadero sitio. Y lo primordial: que España sea España. ${ }^{28}$

La religión bien representa por sí sola un importante bloque para analizar. Los textos que arremetan contra las medidas anticlericales y la cuestión religiosa, en general, van a ser un tema clave y típico de la prensa conservadora del momento. El primer ejemplo al respecto lo encontramos con la publicación de las leyes del divorcio", trámite que no se con buenos ojos: la defensa de la celebración de la Semana Santa tras no salir ninguna cofradía a la calle en marzo de 1931; así como la crítica ante la retirada de símbolos religiosos en las escuelas sobre lo que afirma:

Los demagogos hipócritas, los gobernantes ambiciosos, los soberanos disolutos y déspotas, que celebran sus orgías a costa de la miseria y del dolor del pueblo, temblaban ya en sus altares de falsos oídos [...] Los mochuelos y los búhos [SIC] son enemigos de la luz porque les estorba para sus rapiñas. Por eso no es extraño que los libidinosos gobernantes de Roma fueran hostiles a la Cruz [...] Mas como aquella luz inextinguible no les convenía porque disipaba las sombras de la noche

28 “Comentarios ¿Vesania? ¿Maldición?” (10 de septiembre de 1933). El Paleto, p. 1. 
en que tenían sumido al pueblo, a los trabajadores, cuya ignorancia y sudor explotaban usurariamente, había que acabar con ella, y aquellos verdaderos zánganos de la colmena social, aquellos chupópteros insaciables de los obreros, [...] Este César, cuyo espíritu se había formado evangélicamente, no adoptó el sistema sanguinario y cruel de sus antecesores, sino el de arrojar a los católicos de los cargos públicos, prohibirles toda manifestación paladina de su fé [SIC], suprimir los signos exteriores del cristianismo; y para evitar la formación cristiana del alma de los niños mandó retirar de las escuelas todo cuanto pudiera inclinarlas al amor del Divino Crucificado [...] El Galileo, Cristo, es hoy tan perseguido como en tiempos de los romanos porque la historia, que no es más que un encadenamiento de hechos, suele repetirse a lo largo de los siglos, y viéndolo estamos [...].

Del mismo modo, el enfrentamiento entre la Iglesia y las izquierdas también se verá reflejado en sus páginas al tratar la oposición existente entre ambas.

La educación, por su parte, también dará forma a diversos artículos. El Paleto, desde el punto de vista regeneracionista que mostraba en los primeros años del siglo XX, abogó por una educación de calidad. Eso sí, destacando en aquellos posibles casos, la labor, al respecto, de personalidades de talante conservador, como en el caso de Don Jaime Oriol $^{29}$ :

[...] hay que reconocer la actividad incansable a favor de su pueblo por don Jaime Oriol, para quien desde estas modestas columnas rendimos - al igual que para todos los señores que cooperaron en la gestión - nuestro leal tributo de gratitud; y les exhortamos a que no desmayen en su loable demanda para hacer valer nuestro legítimo derecho, hasta que se nos otorgue justicia completa restituyéndole a nuestro Instituto su primitiva categoría de Nacional. ${ }^{30}$

La crítica al comunismo y otras ideologías de izquierdas así como la oposición a las huelgas, también tuvieron su espacio en los años de la República. El diario muestra, en diversas ocasiones durante el periodo republicano, una actitud combativa al respecto:

\footnotetext{
29 "Sobre Jaime Oriol, sus convecinos Morales Lebrón, Calle López y Cruz Cordero testificaron que había sido "Maurista" y después "Diputado a Cortes por las Derechas en Sevilla", pero que en Osuna nunca se inmiscuyó en política ni fue cacique. [...] El arcipreste de Osuna, Francisco Javier Govantes García, dijo de Oriol que fue diputado de Acción Popular y había sido durante toda su vida un arraigado hombre de derechas, que hasta sufrió persecución de "marxistas y otros sectarios" y que desde los primeros momentos participó personalmente con las armas a favor del "Movimiento Gloriosísimo Salvador de España" [...] En cuanto al capitán de la guardia civil, Rodríguez Hinojosa, éste aseguró en su informe que Oriol había pertenecido a los partidos de derechas y se hallaba adherido al "Glorioso Movimiento Nacional- Sindicalista Salvador de la Patria" desde su inicio [...] en MONTERO GÓMEZ, F.J.: Osuna, 20 de julio de 1936, online:
}

http://www.todoslosnombres.org/sites/default/files/investigacion249_1.pdf, p. 348

30 “iTenemos Instituto!” (11 de octubre de 1935). El Paleto, p. 2. 
[...] Jamás en nuestra Patria se cometieron tamañas crueldades; jamás la sangre española se ha vertido con tanto dolor, al impulso de locos extremistas que se han valido de la libertad y la democracia para dar rienda suelta a sus instintos perversos [...] Y son ellos, los socialistas y las llamadas izquierdas republicanas, quienes alentaron día tras día, desde sus elevados enchufes, al pueblo ciego, a las masas que, fanatizadas, obedecieron a sus líderes mientras ellos "satisfechos", gozaban de las más variadas prebendas y corrían asustadizos como tristes mujerzuelas $[\ldots]^{31}$.

Aplausos al gobierno central y a la labor de los consistorios municipales o las críticas vertidas al antiguo régimen caciquil así como la defensa de ideas retrógradas - en contra del carnaval o del papel de la mujer en las funciones públicas, nuevamente -, serán otras temáticas minoritarias que aparecerán en este periodo.

\section{Conclusiones}

Llegados al punto, podemos concluir que la postura del periódico va a ser progresista y crítica pero dependiendo del momento histórico en el que nos encontremos.

Echando la vista atrás, observamos que los dos primeros años de vida del rotativo fueron más críticos. Lo cual se debe, en primer lugar, a la labor realizada por su redactor jefe, Eulogio Jurado. Entre sus principales empresas estuvo la lucha contra la construcción de la plaza de toros de la localidad. Tras su muerte, el periódico cambia notablemente de actitud. Esta actitud crítica se debe, en segundo lugar, al momento político, con la presencia de un gobierno liberal en el ayuntamiento de Osuna. Creemos que la línea editorial mantuvo su actitud crítica pero que esta dependió de su relación con el poder: fue negativa con el partido liberal y positiva con el conservador.

Efectivamente, hemos podido demostrar que la actitud de El Paleto estuvo muy condicionada por el poder político. Su posición con respecto a la política municipal o nacional fue, sin apenas excepciones, de apoyo y aplauso a los gobiernos conservadores, y de crítica a los políticos y jefes liberales durante la Restauración. Esta cuestión se pone claramente de manifiesto durante el primer periodo histórico analizado al comprobar una mayoría de críticas al respecto. Durante el año 1903: gobierno liberal, con 17 artículos frente a los aplausos a los gobiernos conservadores de 1914 y 1915, con 15 y 16 publicaciones, respectivamente. Claramente, el rotativo realza la labor de los políticos conservadores en contraposición a la ejercida por los liberales. De igual modo,

\footnotetext{
31 “Los crímenes de la revolución” (31 de octubre de 1934). El Paleto, p. 1.
} 
mostrará su simpatía hacia el régimen dictatorial mientras que ante la República mostrará sus críticas.

Consecuentemente, y a pesar de mostrar interés por aspectos importantes para la evolución de Osuna y España como pueden ser la educación o la cultura, no adoptó un punto de vista, precisamente, liberal o progresista. Todo lo contrario, se acredita como un medio conservador que va a exhibir su postura más crítica en el momento en el que el poder se encuentre un gobierno liberal - durante la Restauración - o republicano mientras que su apoyo lo mostrará a los partidos conservadores del turnismo y a la propia Dictadura de Primo de Rivera.

Finalmente, hemos de resaltar la importancia de haber podido leer, digitalizar los números analizados y estudiar el contenido del periódico más longevo de Osuna. Nos ha permitido observar cómo fue evolucionando con los años y atendiendo a los cambios políticos que, a nivel nacional, tenían lugar y que, consecuentemente, se reflejaban a nivel local.

Hemos observado la evolución de la prensa local durante este periodo de tiempo siendo este uno de los objetivos a comenzar estas páginas.

De este modo, se ha intentado exponer la relevancia de un periódico que, a pesar de las dificultades citadas y los momentos convulsos de los que fue protagonista, estuvo publicándose en la ciudad de Osuna un total de treinta y cuatro años. Manteniéndose a pesar de los cambios políticos y de dirección y consiguiendo adaptarse a las circunstancias de cada momento.

\section{Referencias bibliográficas}

ALMUIÑA, C. (1991): "Fondos y metodología para el análisis de la prensa local" en Fuentes y métodos de la Historia local, Instituto de Estudios Zamoranos Floian de Ocampo. Zamora.

ÁLVAREZ, R., ZAMORA, M. y LEDESMA, F. (2000): La vieja prensa de Osuna y El Paleto $2^{a}$ Época. Fundación se Cultura "García Blanco" del Ayuntamiento de Osuna. Osuna.

ÁLVAREZ SANTALÓ, R. (1986): “Osuna y su prensa en los últimos años del siglo XIX" en Archivo Hispalense: Revista histórica, literaria y artística. Tomo LXII (189). Sevilla.

- (1993) Rodríguez Marín, periodista (1880- 1886). Fundación de Cultura “García Blanco" del Ayuntamiento de Osuna. Osuna. 
- (2000) La vieja prensa de Osuna y El Paleto. 2a Época. Fundación de Cultura "García Blanco" del Ayuntamiento de Osuna. Osuna.

BERNAL, A.M. (2003) "Riesgo y ventura de la historia local", en Actas del Primer Encuentro Provincial de Investigadores Locales. Diputación de Sevilla. Sevilla.

BOTRE, A.M.; DESVOIS, J.M. y AUBERT, P. (1981) "Prensa e historia: para una historia objeto de la prensa. La prensa objeto polimorfo de la historia", en Castillo, S. (coord.): Estudios de Historia de España. Homenaje a Manuel Tuñón de Lara. Universidad Internacional Menéndez y Pelayo. Madrid.

BURKE, P. (2006) ¿Qué es la historia cultural? Paidós. Barcelona.

- (2003) Formas de hacer historia. Alianza Editorial. Madrid.

CHECA GODOY, A.; ESPEJO- CALA, C.; LANGA NUÑO, C. y VÁZQUEZ LIÑÁN, M (2007). La Comunicación durante la Segunda República y la Guerra Civil. Editorial Fragua. Madrid.

CHECA GODOY, A. (2010): "Prensa y radio en la Sevilla del Tardofranquismo (19511975)" en Un siglo de información en Sevilla (Prensa, Radio y Televisión). 19091929. Universidad de Sevilla. Secretariado de Publicaciones. Sevilla.

- (2011) Historia de la prensa andaluza. Ediciones Alfar. Sevilla.

DE CERTEAU, M. (1993): La escritura de la historia. Universidad Iberoamericana. México.

DÍAZ DEL MORAL, J. (1967): Historia de las agitaciones campesinas andaluzas. Alianza editorial. Madrid.

GARCÍA ANDREU, M. y SANTACREU, J.M. (1994): "Prensa, sociedad y política provinciana (1902- 1939): el caso de Alicante", en Actas de las Jornadas sobre prensa y sociedad en la Murcia Contemporánea. Departamento de Historia Moderna. Murcia.

GARCÍA GALINDO, J.A. (1999): "La Historia de la Comunicación Social: algunas propuestas en torno a la investigación científica y la docencia universitaria", en GÓMEZ MOMPART, J.L. y MARÍN OTTO, E.: Historia del periodismo universal. Madrid.

GINZBURG, C. (1994): Mitos, emblemas e indicios: Morfología e historia. Gedisa. Barcelona.

LANGA NUÑO, C.; ROMERO DOMÍNGUEZ, L. R.; RUIZ ACOSTA, M. J. ÍNGUEZ, L. R.; RUIZ ACOSTA, M. J. (coord.) (2010): Un siglo de información en Sevilla (Prensa, Radio y Televisión) 1909- 2009. Universidad de Sevilla. Secretariado de Publicaciones. Sevilla. 
LANGA NUÑO, C. (1999): "La prensa sevillana ante los grandes acontecimientos del primer tercio de siglo (1923- 1931)" en REIG, R. y RUIZ ACOSTA, M. J. (coord.): Medios de Comunicación y grandes acontecimientos del siglo XX. Sevilla, Grupo de Investigación en Estructura, Historia y Contenidos de la Comunicación. Colección Ámbitos para la Comunicación, pp. 55 - 101.

- "De la dictadura de Primo de Rivera a la II República", en REIG, R. (dir.) y LANGA NUÑO, C. (coord.) (2011): La Comunicación en Andalucía: Historia, estructura y nuevas tecnologías. Fundación Centro de Estudios Andaluces. Sevilla, pp. 93- 127.

LEVI, G.: "Sobre microhistoria" en BURKE, P. (ed.) (2003): Formas de hacer historia. Alianza Editorial. Madrid, pp. 119- 144.

MOSCO, V. (2006): “La Economía Política de la Comunicación: una actualización diez años más tarde" en CIC: Cuadernos de información y comunicación (11). Universidad Complutense de Madrid. Madrid.

MOSCOSO CAMúÑEZ, M.J. (2017). Estudio de la prensa en Osuna. El paleto ante los distintos regímenes políticos de la España de 1902-1936. Tesis doctoral. Universidad de Sevilla. Puede consultarse https://idus.us.es/xmlui/handle/11441/71288

PASCUAL RECUERO, P. (1986): “Antonio Ma García Blanco y el hebraísmo español del S. XIX" Granada, Universidad.

RAMÍREZ OLID, J.M. (1999): Osuna durante la restauración: 1875- 1931. Volumen I y II. Ayuntamiento de Osuna. Osuna.

REIG, R. y RUIZ ACOSTA, M.J. (1998): Sevilla y su prensa. Aproximación a la historia del periodismo andaluz contemporáneo (1898-1998), Universidad de Sevilla; Grupo de Investigación en Estructura, historia y contenidos de la Comunicación. Sevilla.

REIG GARCÍA, R. (2007): El periodista en la telaraña. Anthropos. Barcelona.

RUIZ ACOSTA, M. J. (1998): Historia general de la comunicación: escritura y prensa. MAD. Alcalá de Guadaira (Sevilla).

- (1999) "Prensa y asociacionismo: el gran reto de los diarios sevillanos de principios del siglo XX" en REIG GARCÍA, R. (coord.) y RUIZ ACOSTA, M. J. (coord.): Medios de comunicación y acontecimientos del siglo XX. Universidad de Sevilla: Grupo de investigación en Estructura, Historia y Contenidos de la Comunicación. Sevilla.

- (1999) "Prensa y profesión informativa: la visión de los periodistas sevillanos de principios del siglo XX" en BARRERA DEL BARRIO, C. (coord.): Del gacetero al profesional del periodismo. Evolución histórica de los actores humanos del cuarto poder. Fragua: Asociación de Historiadores de la Comunicación. 
SÁNCHEZ MORILLO, A. (2007): "La prensa en Osuna: contexto y fuentes", en Cuadernos de los Amigos de los Museos de Osuna, no. 9. Osuna.

SÁNCHEZ MORILLO, A.: y AGUILAR MAJARÓN, I. (2006): “El periodismo en Osuna: una etnografía del oficio", en Cuadernos de los Amigos de los Museos de Osuna, №. 8. Osuna.

SECO SERRANO, C. (1979): Alfonso XIII y la crisis de la Restauración. Rialp. Madrid.

- (1991) "Crisis e ideología en la restauración" en TUÑÓN DE LARA, M.: España entre dos siglos (1875-1931). Continuidad y cambio. Siglo Veintiuno de España Editroes. Madrid.

SHUBERT, A. (1999): Historia social de España (1800-1900). Editorial Nerea. Madrid.

SIMÓN PALMER, M. C. (1991): "La prensa local como fuente de la "pequeña historia" en La Prensa Española durante el siglo XIX. I Jornadas de Especialistas en Prensa Regional y Local. Ediciones Instituto de Estudios Almerienses. Almería.

SORIA MEDINA, E. (2004): Desde la Colegial (Miscelánea Ursaonense: 1954- 2001). Diputación de Sevilla, Fundación El Monte, Ayuntamiento de Osuna y Caja San Fernando: Obra social.

TUÑÓN DE LARA, M. (1974): La España del siglo XX. La quiebra de una forma de Estado (1898/ 1931) 1. Editorial Laia. Barcelona.

VÁZQUEZ MONTALBÁN, M. (1982): Historia y comunicación social. Alianza Editorial. Madrid. 